\title{
CLINICAL CAIORIMETRY
}

\author{
SECOND PAPER
}

\section{THE RESPIRATION CALORIMETER OF THE RUSSELL SAGE INSTITUTE OF PATHOLOGY IN BELLEVUE HOSPITAL *}

\author{
J. A. RICHE AND G. F. SODERSTROM \\ NEW YORK \\ CONTENTS
}

1. Previous descriptions of calorimeters.

2. The calorimeter toom.

3. The wooden frame.

4. The copper walls and the insulating wall.

5. The absorber table, spirometer and heat absorbing system.

6. Rheostat board and observer's table.

7. Electric thermometers.

8. Telephone, fan and bed.

9. Electric and alcohol control experiments.

10. Limits of error in measuring heat, carbon dioxid and oxygen.

11. Determination of water elimination.

12. Adaptability of calorimeter to varying conditions.

13. Summary and conclusions.

During the short time in which the Sage calorimeter has been in operation there have been several requests for the technical details of the construction of the apparatus. It has therefore seemed advisable to publish a brief article for those interested in calorimeters. A complete description of the Atwater-Rosa-Benedict type of apparatus will be found in the monograph by Benedict and Carpenter. ${ }^{1}$ A number of valuable improvements are added in the shorter article by Williams. ${ }^{2}$ The earlier publications of Atwater and $\mathrm{Rosa}^{3}$ and Atwater and Benedict ${ }^{4}$ describe an apparatus fundamentally the same as that now employed, but for a complete understanding of the modern calorimeter it is necessary to consult the works of Benedict and Carpenter and

* Submitted for publication Oct. 20, 1914.

* From the Russell Sage Institute of Pathology, in affiliation with the Second Medical Division of Bellevue Hospital.

1. Benedict and Carpenter: Respiration Calorimeters for Studying the Respiratory Exchange and Energy Transformations of Man, Carnegie Institution of Washington, 1910, $\mathrm{Put}$. 123.

2. Williams, H. B.: Animal Calorinetry, First Paper, A Small Respiration Calorimeter, Jour. Biol. Chem., 1912, xii, 317.

3. Atwater and Rosa: Description of a New Respiration Calorimeter, U. S. Dept. Agriculture, 1899, Bull. 63.

4. Atwater and Benedict: A Respiration Calorimeter with Appliances for the Direct Determination of Oxygen, Carnegie Institution of Washington, 1905, Pub. 42. 
Williams. The description by Langworthy and Milner ${ }^{\overline{0}}$ of their ingenious automatic calorimeter should also be consulted.

The Sage calorimeter resembles Benedict's bed calorimeter, but differs in a few details. On the recommendation of Dr. Langworthy and Mr. Milner of the Department of Agriculture the outside insulation was made of pressed cork and "Compo Board." The electrical resistance thermometers for the ingoing and outgoing water were also adopted on their advice. The gas wash bottles, water heating resistance and current regulator, water coil and several other improvements were copies of those used by Williams. The soda-lime bottles and spirometer resembled those described by Benedict ${ }^{6}$ in connection with his small apparatus.

\section{THE CAIORIMETER ROOM}

The small metabolism ward to be described is situated at the southwest corner of the new medical pavilion of Bellevue Hospital. To the north of this is a hall, now converted into a diet kitchen, which leads into the calorimeter room, formerly a small ward for convalescents. The room itself (Fig. 3 ) is about 5 meters square and 5 meters high. On the west side, opening on a covered balcony, is a large window in front of which stand a thermostat-controlled radiator and a "Simplex" electric heater. These are enclosed in a window box in such a manner, that by means of a blower, fresh air can be drawn in through the window, driven over the heaters and out into the room. Unfortunately, the daylight is not strong and needs to be supplemented by two powerful tungsten lamps.

In the center of the room stands the calorimeter, at the side of which is the observer's platform, raised a short distance above the floor to permit the passage of the numerous water pipes and electrical conduits. On the east side of the room is the panel box where the heavy feed wires are led up from the basement. Next to this panel box are the storage batteries with charging board used in electric checks. On the south side of the room, where the door is situated, enough space has been left to wheel a stretcher with a patient to the front of the calorimeter. By making careful use of every inch a great deal of apparatus has been placed in a small room without crowding those who work there.

\section{THE FRAME}

Is the photographs show, the calorimeter was made high enough at the head to allow the subject to sit upright. This increases the

5. Langworthy and Milner: Year Book U. S. Dept. Agriculture, 1910, p. 307 ; ibid., 1911 , p. 491.

6. Benedict, F. G.: Ein Universalrespirationsapparat, Deutsch. Arch. f. klin. Med., 1912, cvii, 156. 


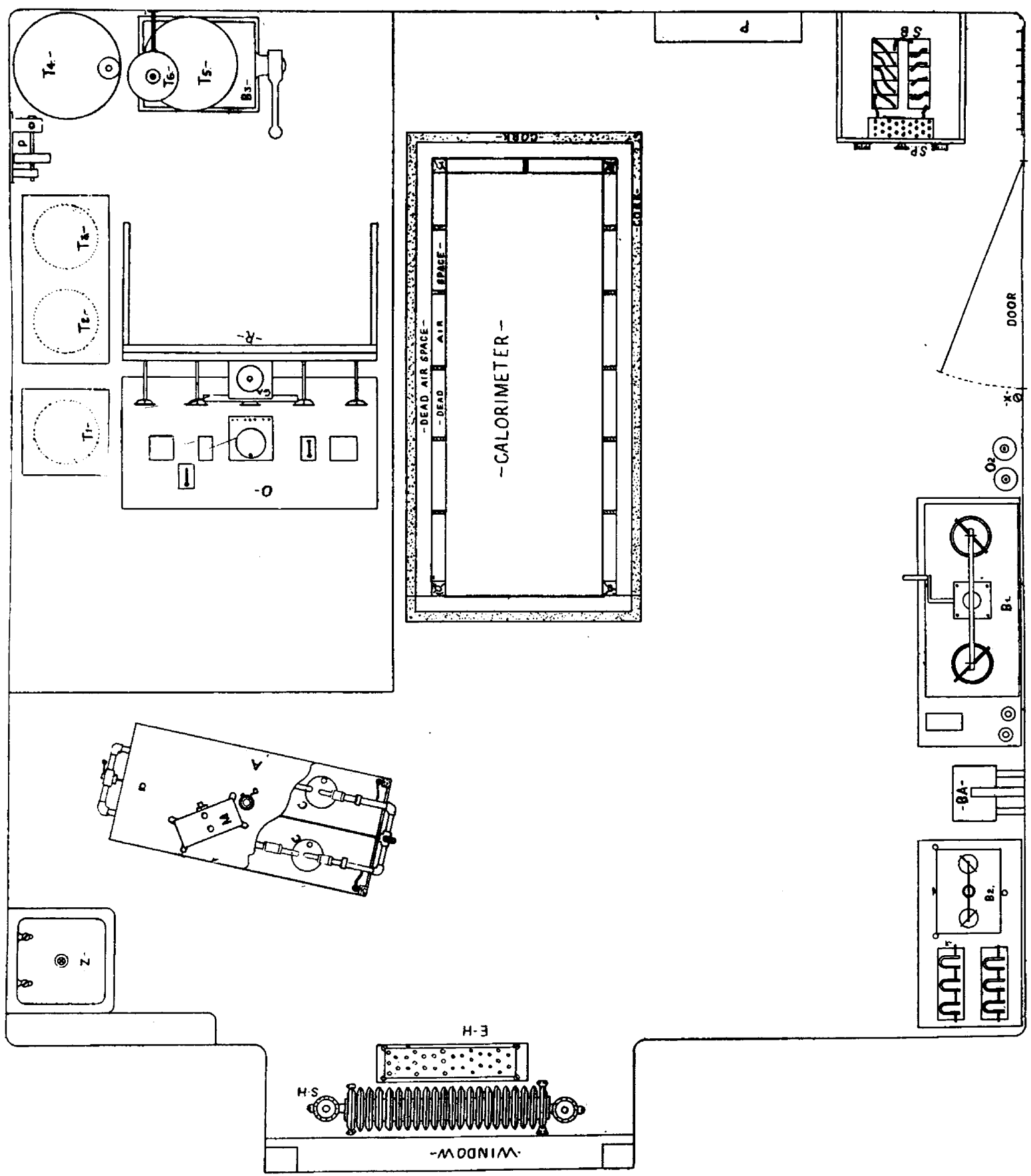

Fig. 3.-The calorimeter room. A, Absorber tabl e. M. Bohr meter. b. Drying tower for air sample drawn through meter. CC, Williams bottles contain ing sulphuric acid. SH, Steam heater. EH, Electric heater. Z, Sink. O, Observer's table. Ga, Galvano meter. $R$, Rheostat board. $T_{1}$, Gouy regulator tank. $T_{2}$. Ice tank for cooling water running through abso rber in calorimeter. $T_{3}$. Ice tank for water to cool outer copper wall. $T_{4}$, Large supply tank. $T_{5}$, Tank on platform balance $\left(B_{3}\right)$ for weighing water. $T_{6}$, Small tank to hold water from absorber while $T_{5}$ is being weighed. $p$, Pump to lift water from $T_{4}$, to constant-level tank near the ceiling. $P$, Panel box. S B. Edison storage batteries. SP, Charging panel. $x$, Pyrene fire extinguisher. O, Oxygen tanks. $\mathrm{B}_{1}$, Balance for sulphuric bottles, etc. $\mathrm{Ba}$, Barometer. $\mathrm{B}_{2}$, Balance for U-tubes. 
volume of contained air and magnifies certain errors, but makes the box much more comfortable and apparently gives better results than if the quarters were cramped. The frame (Fig. 4) was made of wood, as previous experience with the small calorimeter in Cornell had shown that the mass of angle iron between the metal walls made the box very sluggish in responding to temperature changes. To prevent warping, which would be disastrous, the best quality white pattern pine was used and the frame allowed to stand for several months before it was shellacked. The outside timbers were 6.35 by $6.35 \mathrm{~cm}$. square and the braces 6.35 by $1.9 \mathrm{~cm}$. All joints were glued and dowelled. The braces were spaced $30.48 \mathrm{~cm}$. apart to give rigidity to the copper walls which are attached to the wood in many places.

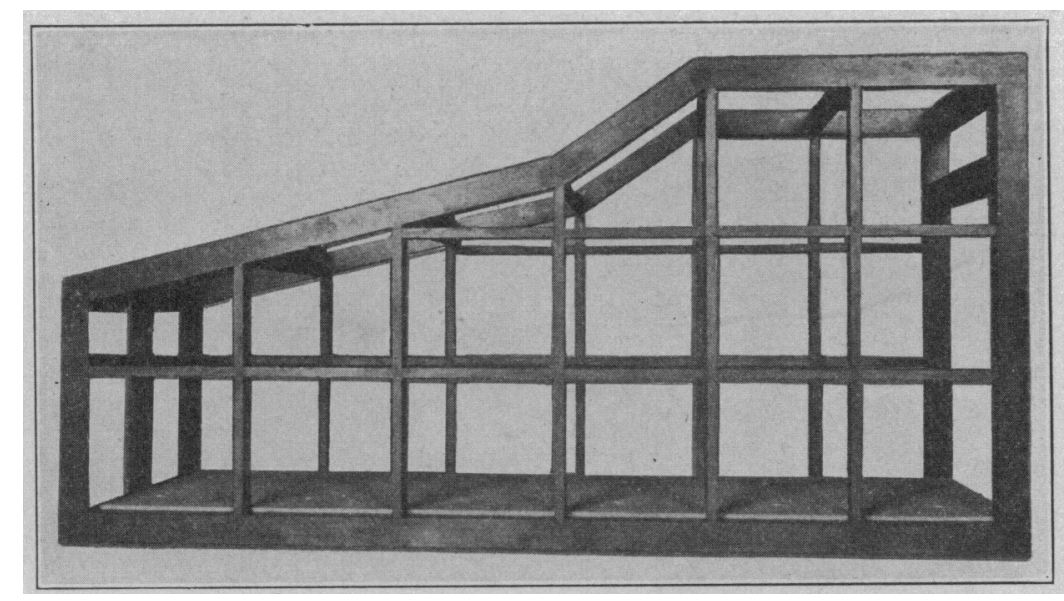

Fig. 4.-Wooden frame of calorimeter with asbestos board as floor.

\section{COPPER WALLS}

The inner copper wall (Fig. 5) forms an air-tight box $198.18 \mathrm{~cm}$. long, $76.2 \mathrm{~cm}$. wide, $91.4 \mathrm{~cm}$. high at one end and $45.7 \mathrm{~cm}$. at the other, with a capacity of 1,123 liters. At the head is an opening to serve as a door and on one side an opening for a window.

The wall is made of "16-ounce" sheet copper, tinned on the inside. lt is fastened to the inner side of the wooden frame by means of brass angles soldered to the copper and screwed to the wood. The bottom rests on a long slab of asbetos board $9.5 \mathrm{~mm}$. thick.

The outer copper wall (Fig. 6) which is screwed directly on the outer side of the wooden frame, does not come in metallic contact with the inner wall at any place except the rim around the large opening at the head of the box. This outer wall is made of "14-ounce" copper tinned on the outside, and while the joints are soldered they are not necessarily air-tight. 


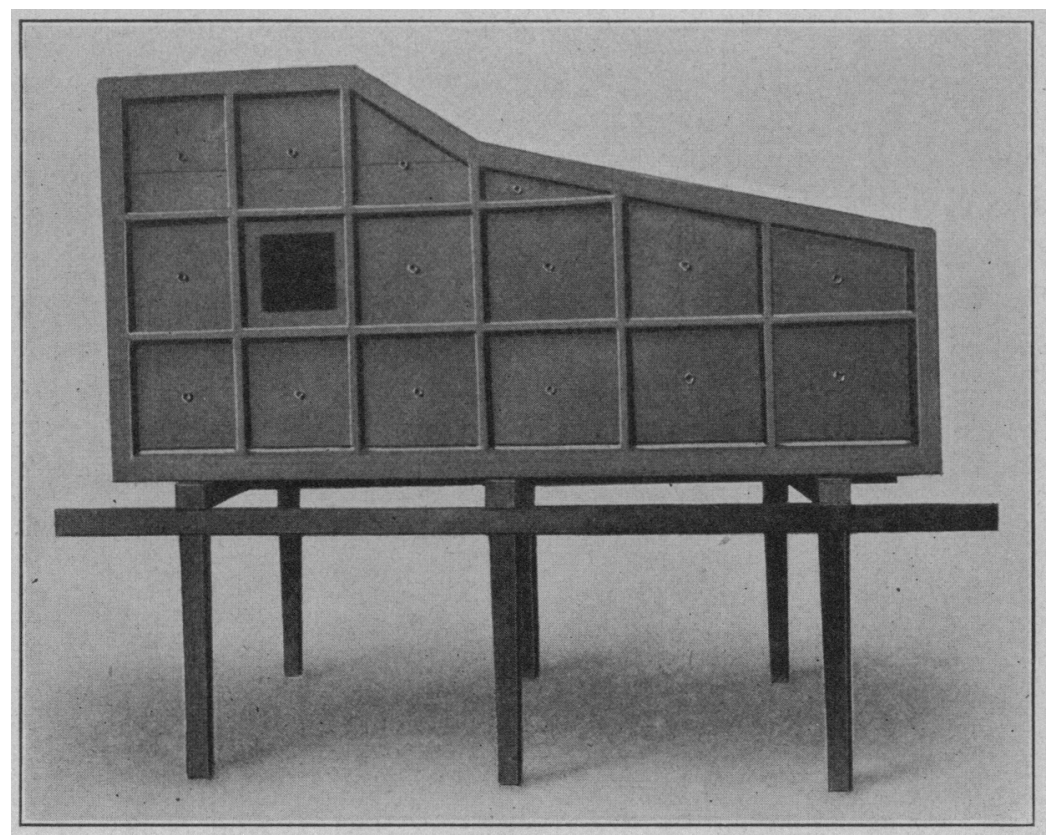

Fig. 5.-Inner copper box with brass thimbles for thermopiles.

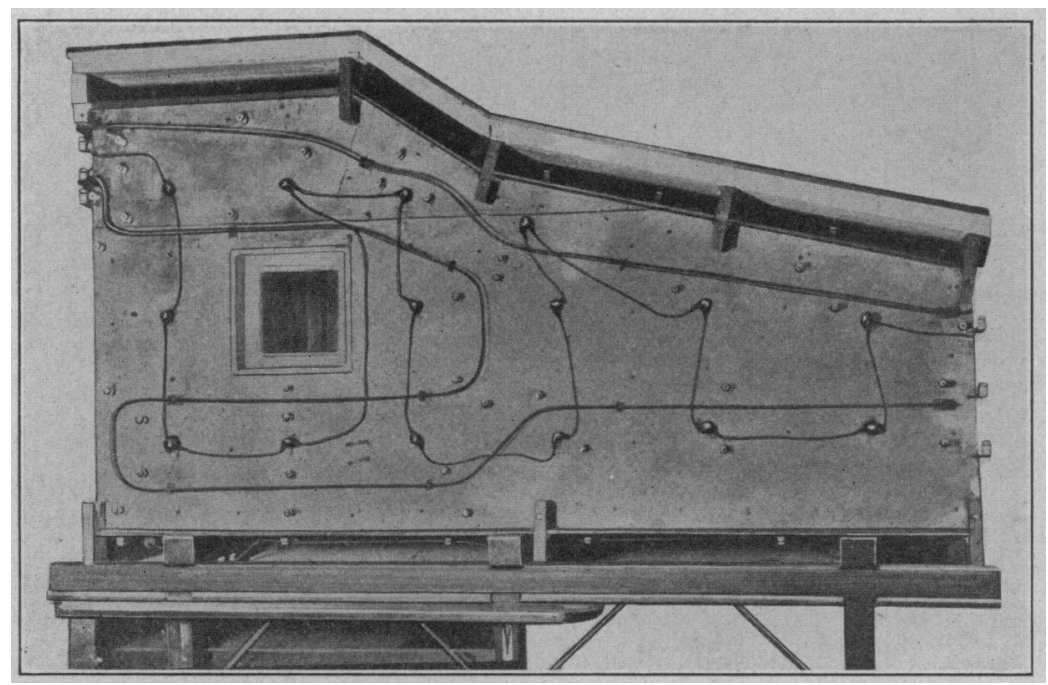

Fig. 6.-Outer copper box with leads connecting thermopiles. pipes for cold water and porcelain insulators for resistance wires. The wires themselves are not shown in the photograph. The top and botton of the woolen box are in position. 


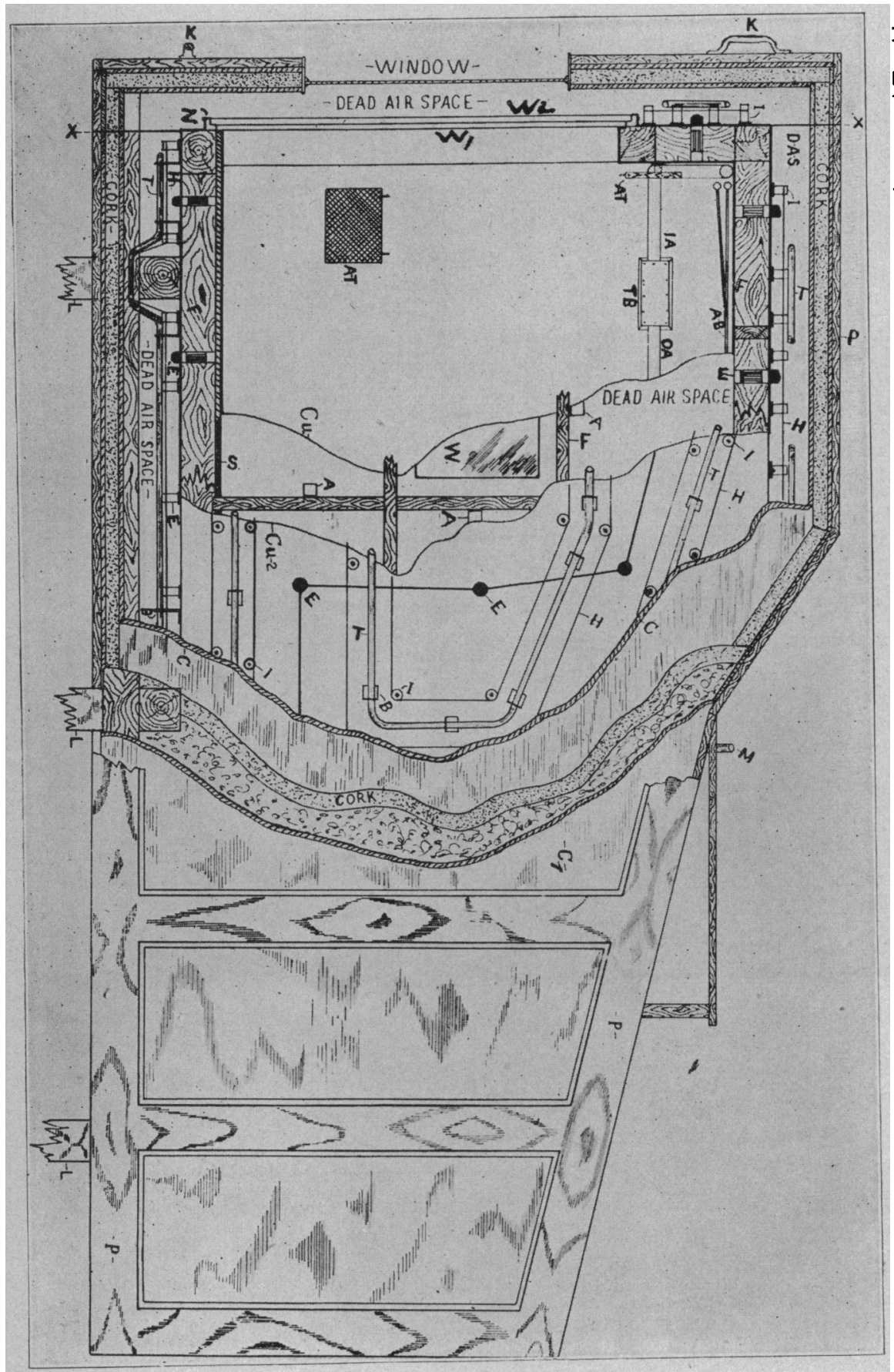

云志矛语兽

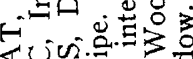
यर्या i.

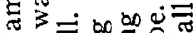

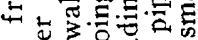

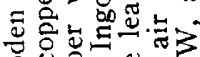

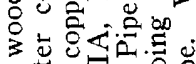
ㅇㅎㅀ

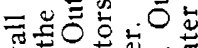

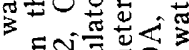

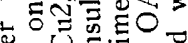
屾声司

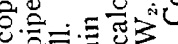

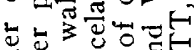
E 3 国 位

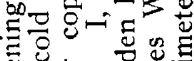
过造焉

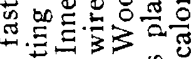

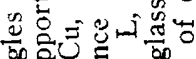
है $=$. क

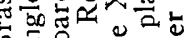

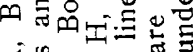
近记范

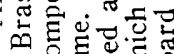

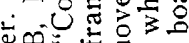
计 E 的完 $x$ ○

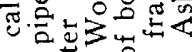

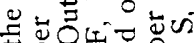
士

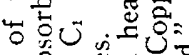
30 总

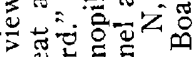

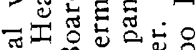
펌 की०

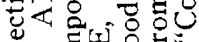
क ० 1. 过 人

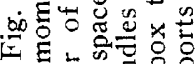
空击密出 
The braces of the wooden frame divide the dead air space between the walls into compartments about $30.48 \mathrm{~cm}$. square and $6.35 \mathrm{~cm}$. thick. In the center of each compartment is placed a thermopile with four thermocouples in thermal but not in electrical contact with each copper wall. The inner end of this thermopile fits in a brass thimble $25.4 \mathrm{~mm}$. deep soldered to the outer side of the inner wall. The outer end (with its four thermocouples) fits in a brass tube which passes through the outer wall and is closed off from the outside air by P. B. Compound and electric tape.

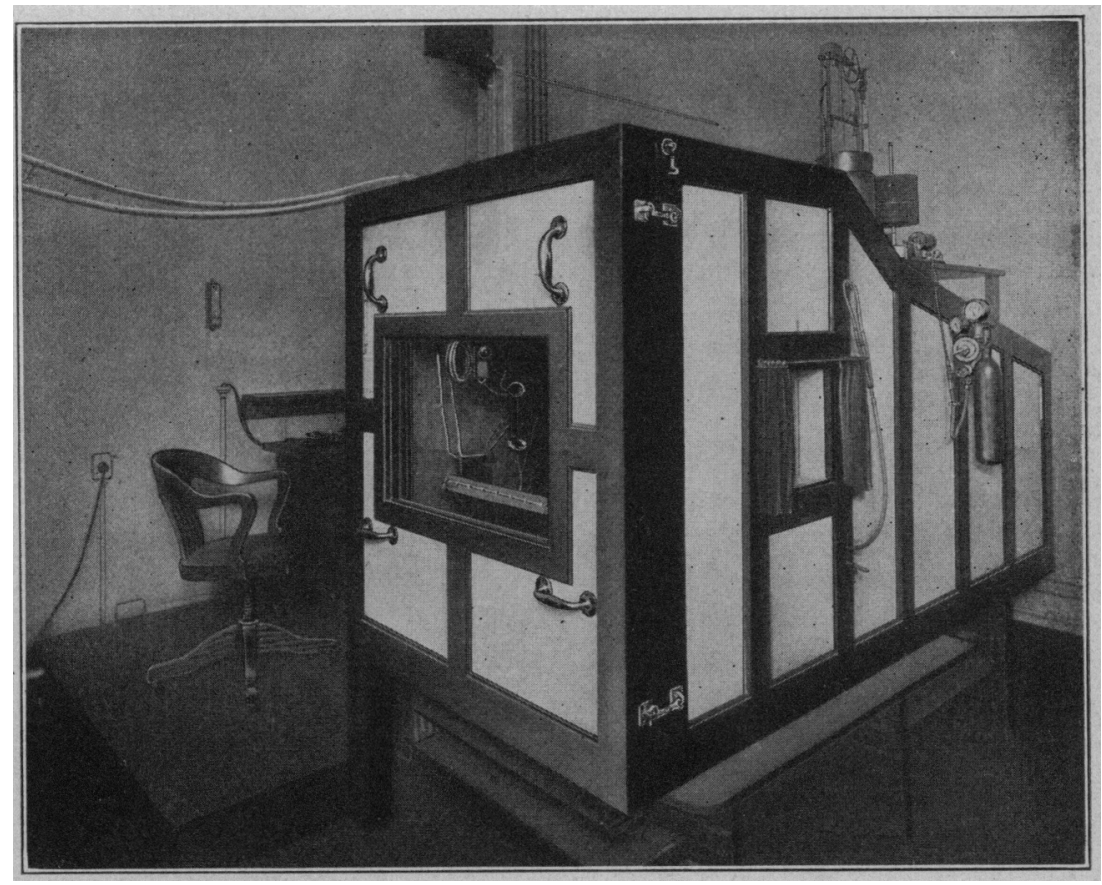

Fig. 8.-Calorimeter with front closed.

In Figure 13 the large opening at the head of the box, measuring 76 by $70 \mathrm{~cm}$., is closed by two glass plates $7.5 \mathrm{~mm}$. thick, each sealed after the subject has entered the calorimeter by means of a mixture of 5 parts bees-wax and $1 \mathrm{r} / 2$ parts Venice turpentine. The small window in Figure 6 is permanently closed by glass plates fastened to the copper walls. There are numerous pipes and electric cables entering the box as will be described later.

On the surface of the outer copper wall are attached the wires connecting the thermopiles. The pipes for cold water are swung on brass angles attached to this surface and the enameled "Therlo" resistance wire is bound on insulators to the same surface, very much as described by Benedict and Carpenter. 
INSULATING WALL

Completely surrounding the outer copper wall and separated from it by a space of $7 \mathrm{~cm}$. is the thick wall intended to protect the calorimeter from fluctuations in the room temperature. This is constructed of a layer of pressed cork $2.54 \mathrm{~cm}$. thick, between two layers of "Compo Board," a patented building material made of strips of wood glued between layers of stout paper. This is supported by a framework of white-wood, making panels which are light, yet very effective as heat insulators. The head of the wooden box is provided with a glass window and furnished with handles so that it can be easily removed when the experiment is over and placed on a small shelf on the right of the calorimeter. The frame of this outer box is stained to resemble oak, and the "Compo Board" panels are painted with white enamel. Every effort has been made to make the room and the calorimeter pleasing to the eye, with the result that patients are attracted by the beauty of the apparatus rather than by its resemblance to a coffin.

THE ABSORBER TABLE

The absorber table is so arranged that the air current is switched from one set of absorbers to the other by means of a three-way valve. This works satisfactorily and is much quicker than the old style seatvalves. The sulphuric bottles are larger models of the form described by Williams and hold about $1 \frac{1}{4}$ liters of acid, which will remove every trace of moisture until more than 100 grams has been absorbed. The soda-lime bottles resemble those devised by Benedict, ${ }^{6}$ except for a modification of the tube which carries the entering air. This is divided in such a manner that the soda-lime can be packed about a brass pipe, the lower end of which is perforated and the upper end of which reaches almost to the top of the bottle, where it fits snugly in an elbow attached to the stopper. The Crowell blower is the same as the ones used by Williams and Benedict, but a safety device has been attached to prevent accidental reversal of the blower which would have disastrous effects. The two small bicarbonate cans next to the last sulphuric bottle did not remove entirely the acid vapors and it was necessary to place a long cylinder in the vertical pipe which carries the air from the absorber table. This contains about 340 grams of bicarbonate of soda packed between layers of cotton and catches all traces of acid fumes.

The air enters the box in a pipe which ends in a single opening directed just above the subject's head and leaves through a number of small openings in a pipe which runs across the foot of the box. A small electric fan at the lower end of the calorimeter keeps the air well stirred. 


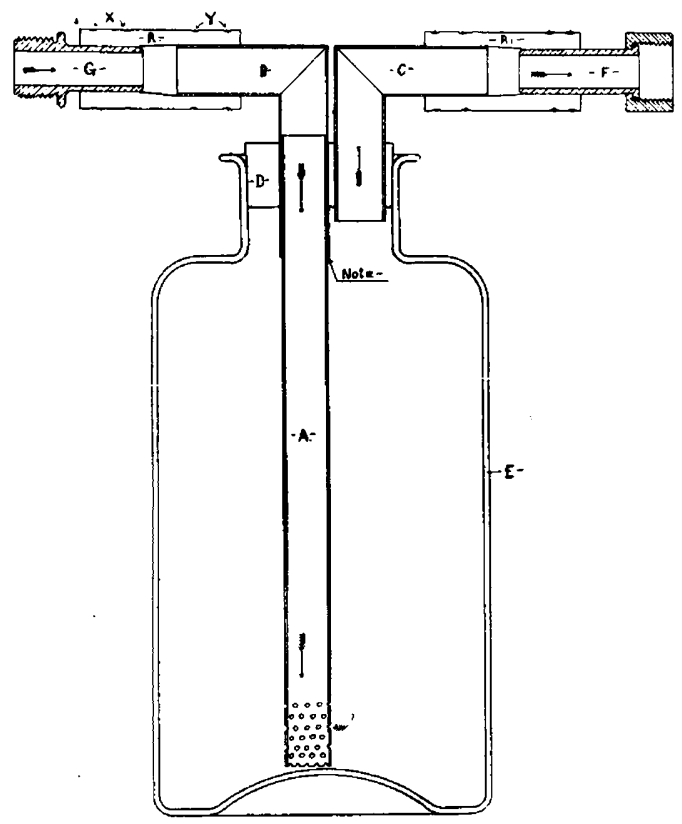

Fig. 9.-Modified soda-lime bottle. A, Brass tube with perforated bottom and top which fits in brass elbow, B. The bottle is filled with $\mathrm{A}$ in position and the rubber stopper $D$ with elbows $B$ and $C$ is then forced into neck of bottle. $G$ and $F$, Brass couplings. $R$ and $R_{1}$, heavy rubber tubing. $X$ and $Y$, Binding wires.

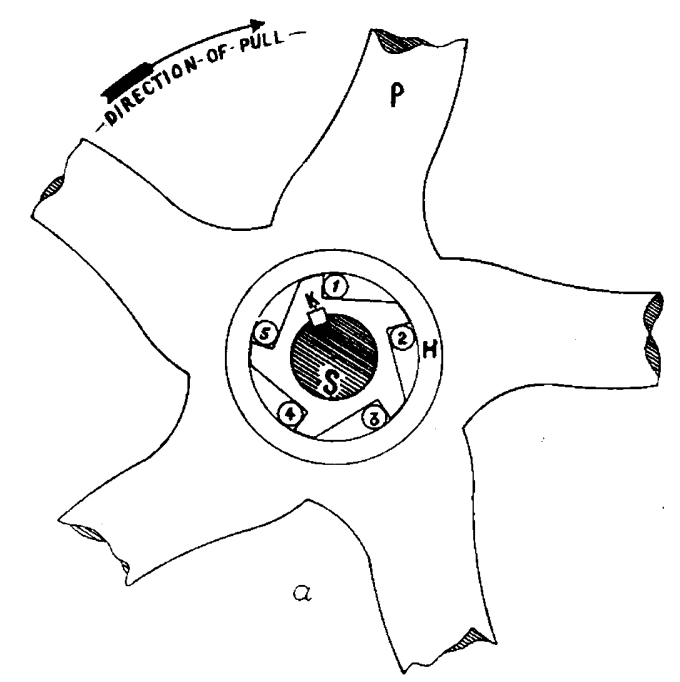

Fig. 10.-Safety device to prevent blower from being reversed. P, Pulley for belt to motor. S, Shaft of blower. H, Hub of wheel. K, Key 1, 2, 3, 4, 5, hardened steel rollers which engage when pulley is running in right direction, but disengage when pulley starts in opposite direction. 

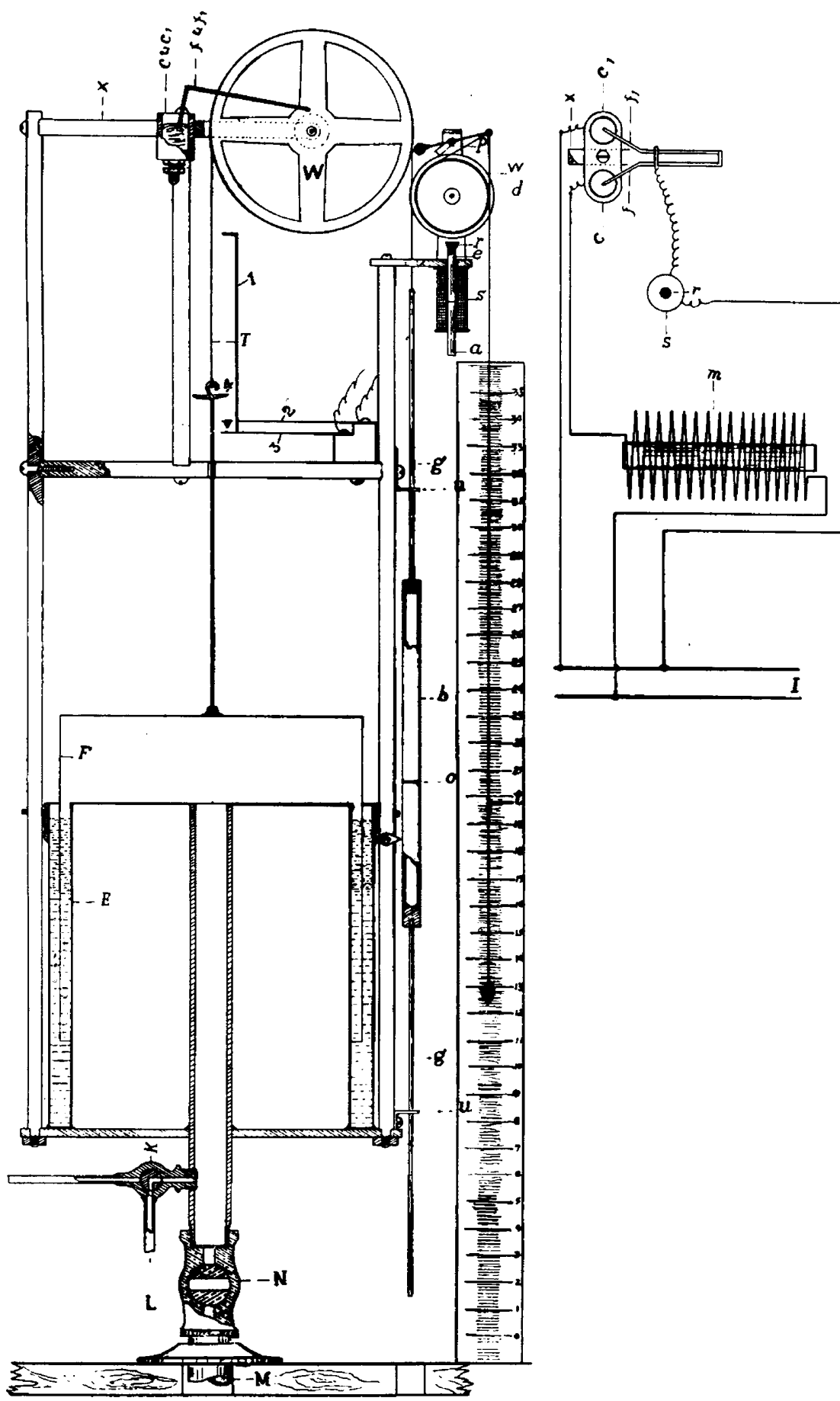

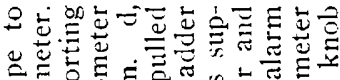

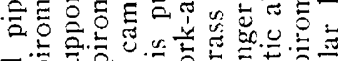

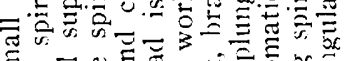

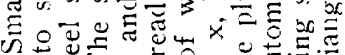

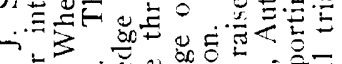
o

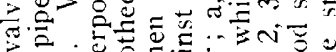

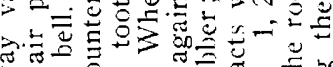
bot

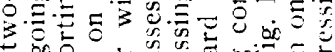
E r.

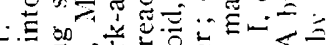

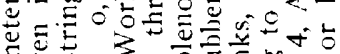

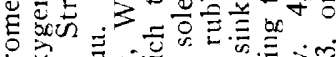

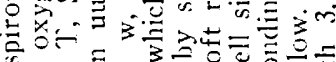

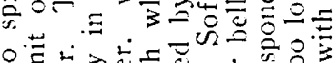

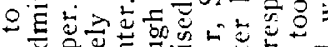

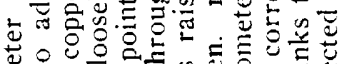

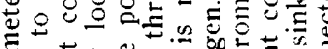

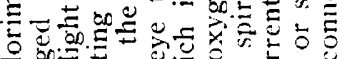

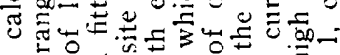
है

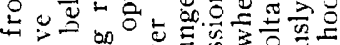

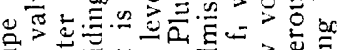

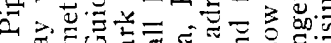

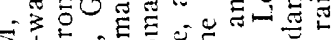

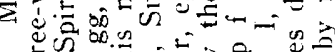
级.

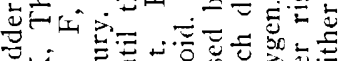

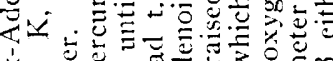

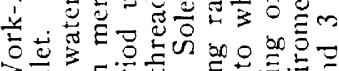

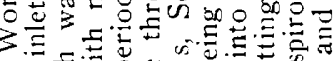

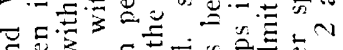

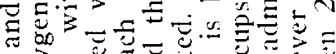

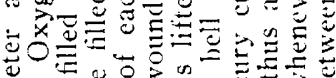

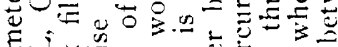
E.

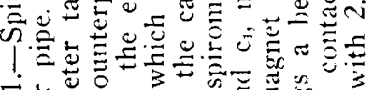

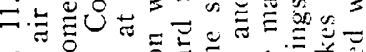

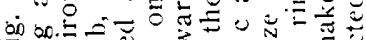
on.

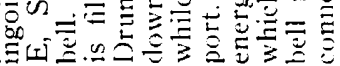


The spirometer on the top of the calorimeter resembles Benedict's ${ }^{6}$ except that it is provided with a work-adder to record movement of the patient and not the total ventilation of the lungs. The bell is made of very light copper, is suspended in water and is carefully counterpoised. The counterpoise is provided with a writing point which records on a smoked paper the movements of the drum. To the wheel at the top is attached a brass arm with two points which dip into mercury cups set at slightly different levels whenever the spirometer bell

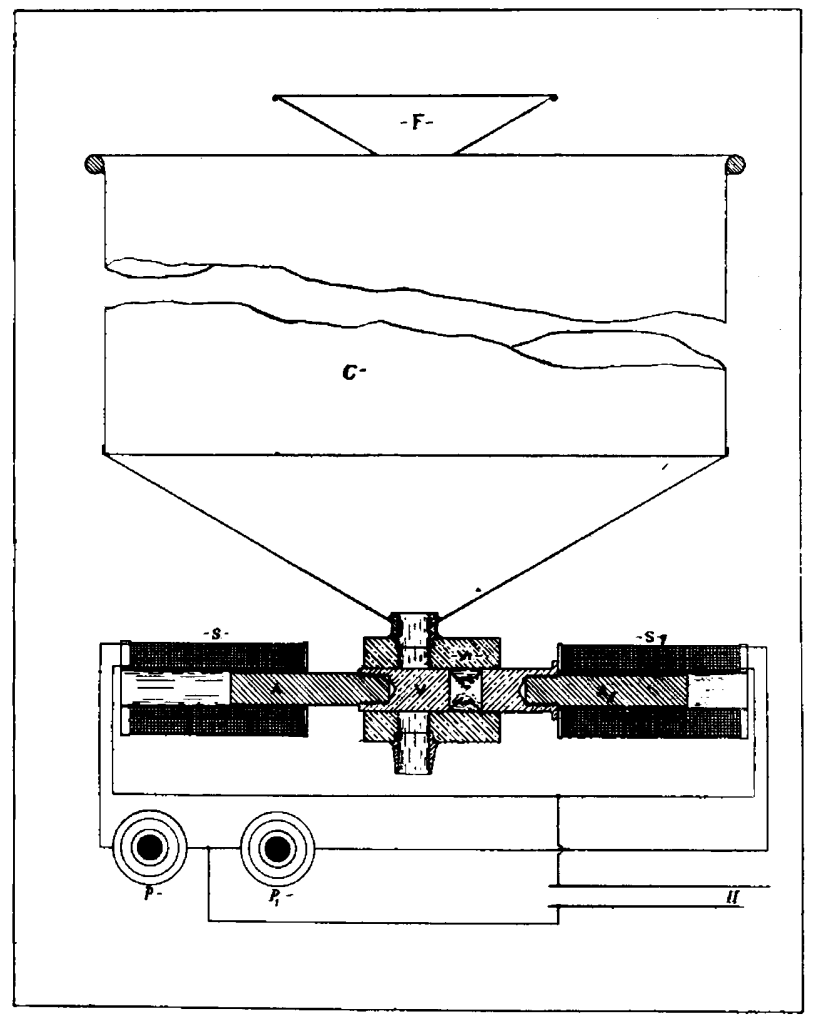

Fig. 12.-Electrical device for shutting and opening valve $P . P_{1}$. Push buttons controlling solenoids $S$ and $S_{1}$. $A$ and $A$, iron cores attached to brass rod V. Valve is shown closed. When current is passed through $\mathrm{S}$ the Rod V will be drawn to the left and the narrow portion seen just under $V_{1}$ will come opposite the pipe leading from receiving can $G$.

sinks below a certain mark. One of these cups operates a magnet which opens the attachment that automatically admits the oxygen. This keeps the spirometer within about one centimeter of the same level unless the subject moves and suddenly heats the air locally. It is remarkable how promptly the spirometer rises when the person within the box makes even a slight movement of a hand or leg. In fact, it makes so delicate a 
movement recorder that a Porter work-adder has been attached in such a manner that the rownward movement of the counterpoise winds un a thread and the total amount of thread so wound represents the total work done by the patient during that particular period. By standardizing various movements of the body such as turning over or lifting the arm it is possible to gain a fairly accurate idea of the amount of mus-

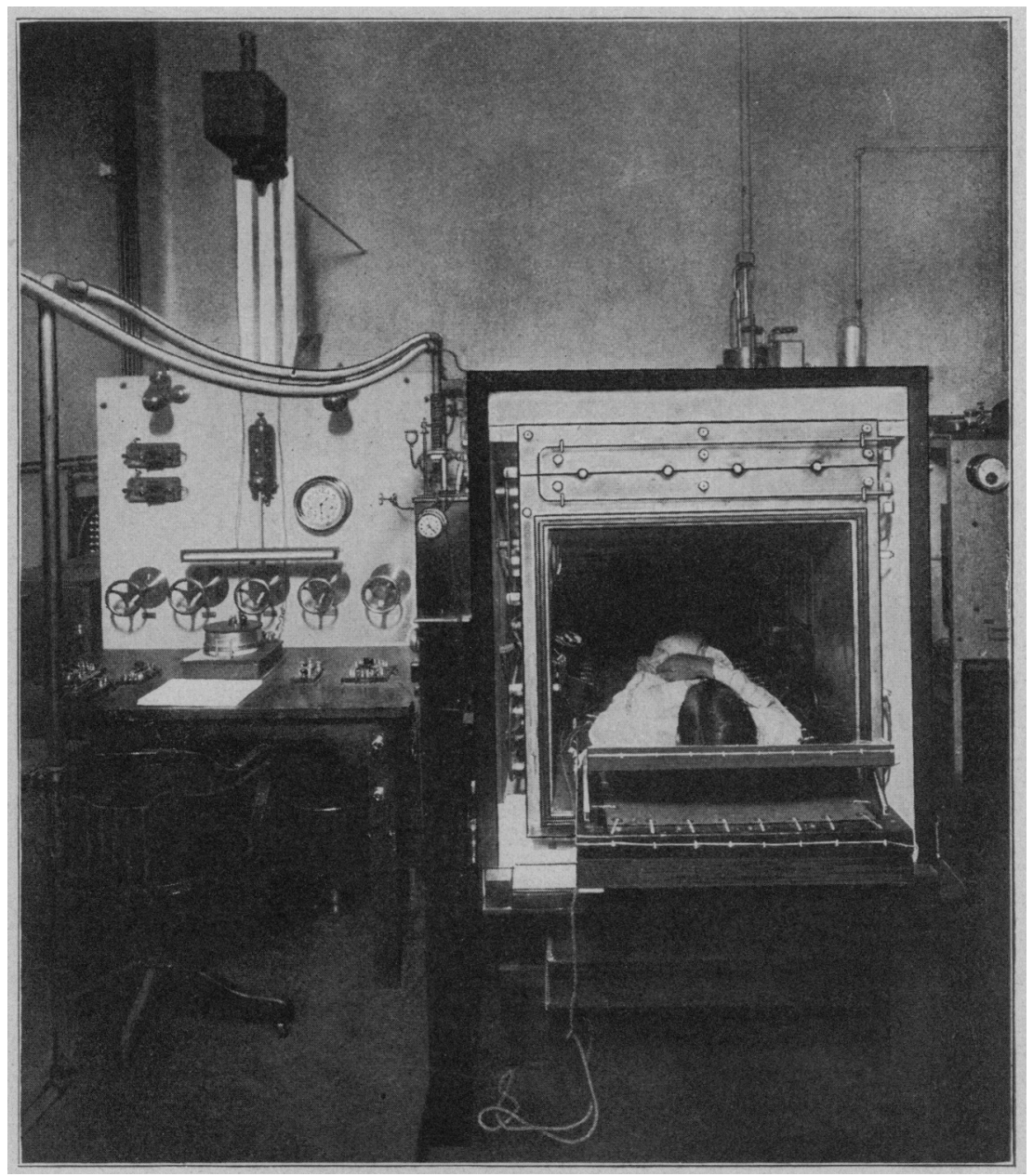

lig. 13.-View of open calorimeter. Patient on canvas bed partly in the chamber. On the left can be seen the observer's table and the rheostat board with the galvanometer. The rubber pipes for outgoing and ingoing air lead to the absorber table. a corner of which can be seen ot the extreme left. In the hackground on the right are the storage hatteries and charging panel.

cular movement and express it in centimeters of thread, thus obviating the necessity of printing long graphic records. In order to prevent the work-adler from winding up thread while the oxygen is being admitted, 

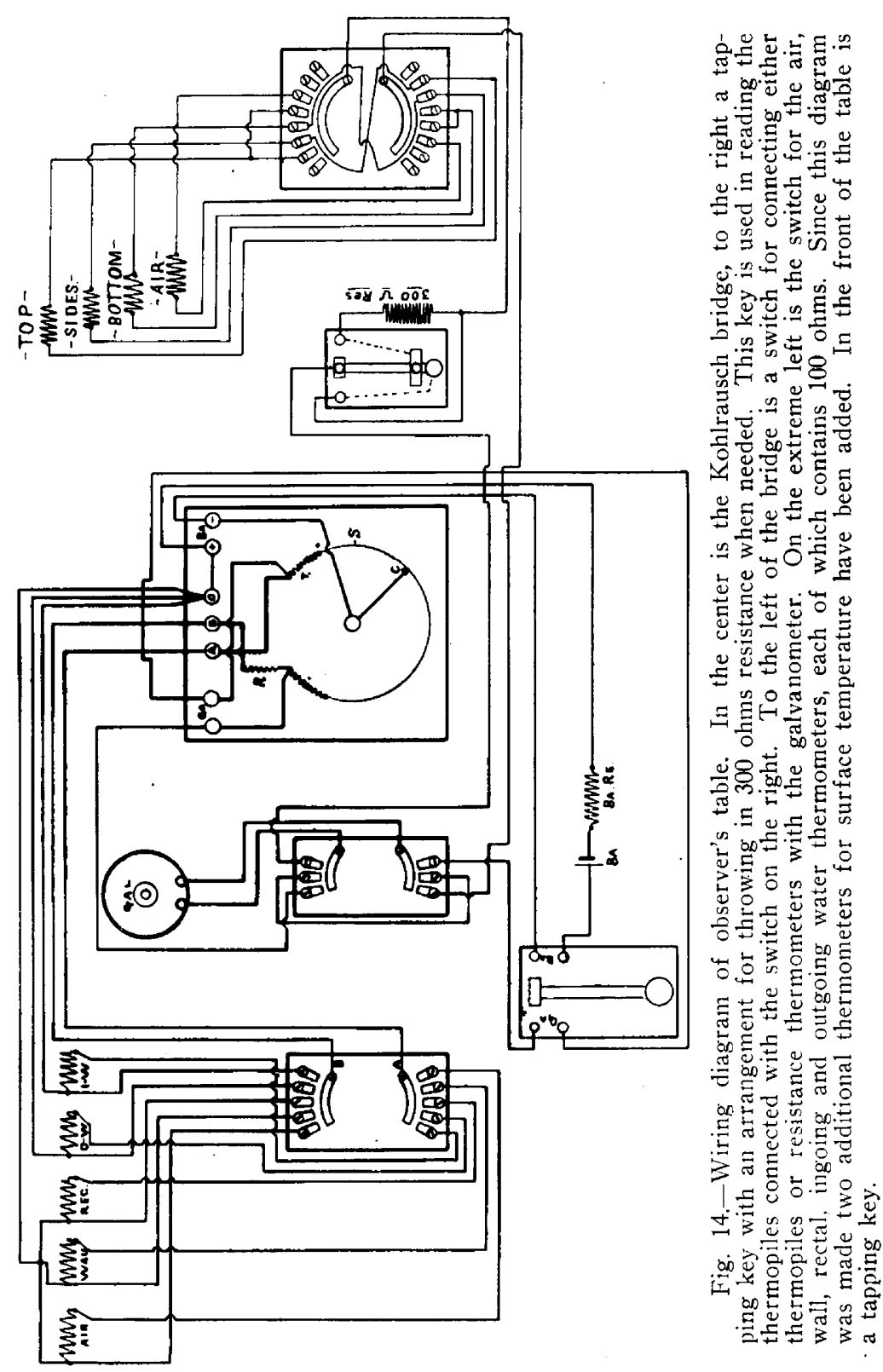
a solenoid is connected with the second mercury cup into which the brass arm on the wheel dips. This solenoid operates a small plunger which holds the work-adder while the magnet opens the oxygen valve and also maintains its hold for the instant after the oxygen has been shut off, since the spirometer rises somewhat slowly after the admission of oxygen. This solenoid lag, which corresponds to the spirometer lag, is secured by having the second mercury cup filled slightly more than the cup which controls the oxygen magnet.

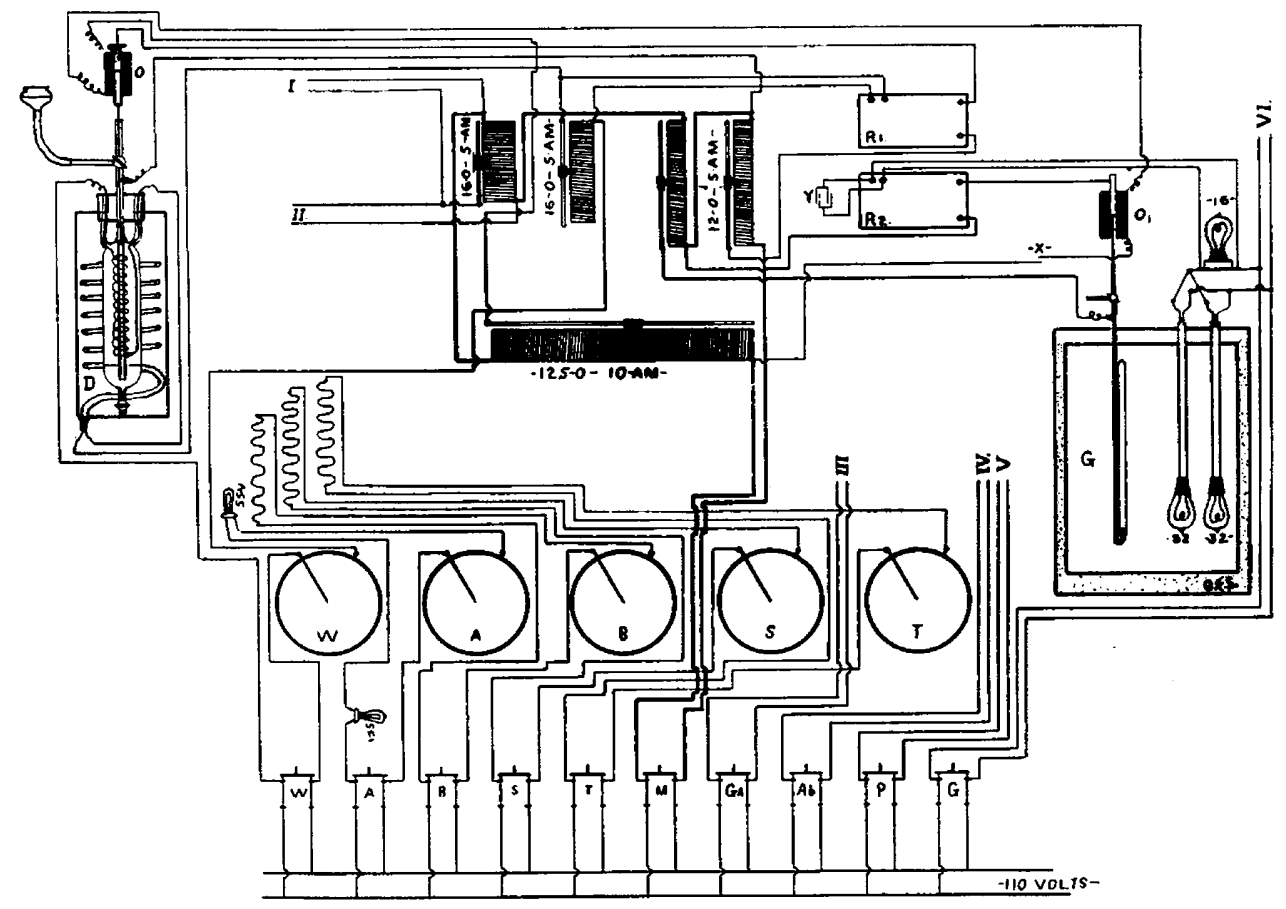

Fig. 15.-Wiring diagram of rheostat board. W, Switch and rheostat to control temperature of ingoing water in water heating resistance, D. A, Ingoing air. B, Bottom of calorimeter. S, Sides. T, Top. Ga, Galvanometer lamp. $\mathrm{Ab}$, Motor on absorber table. P, Motor for pump. G, Lamps in Gouy regulator. $M$, Miscellaneous parts connected with tube rheostats. $O, O_{2}$, Solenoid agitators lifting and dropping platinum contacts with mercury in Gouy and current regulator as the contact is made and broken mechanically at $x . R_{1}$, Relay for current regulator. $R_{2}$, Relay to control heating of lamps in Gouy.

The heat-absorbing system is the same as that described by Williams, the Gouy regulator and Williams' water heating resistance and current regulator giving very satisfactory results. The water coil suspended from the roof of the calorimeter has, however, been wound with brass "jack chain" to increase its absorbing surface. From this coil the water runs to the weighing tank on the platform of a "silk scale" 
which is sensitive within 10 grams. The flow of water was formerly cut off by hand at the end of each period, but this is now done by a pair of solenoids controlled by the operator at the observer's table, thus reducing the staff by one man. The stream of water runs constantly through a can which has the capacity of 10 liters, and is provided at its lowest point with a valve that is opened and shut by the pair of sclenoids above mentioned. At the end of a period the valve is shut and the water collects in the can while the tank is being weighed. After the weighing is finished the valve is opened and the water runs once more into the tank.

\section{RHEOSTAT BOARD AND OBSERVER'S TABLE}

The marble rheostat board and the observer's table resemble closely those described by Williams. This rheostat board, the panel box, charging panel for the storage batteries, conduits, wires, etc., were installed by the Electric Construction Supply Company after specifications kindly drawn up for us by the Department of Water Supply, Gas and Electricity of New York City. Directly above the rheostat board is mounted a galvanometer of the d'Arsonval type, provided with prisms so that the ascending ray of light from the lamp below is reflected from the mirror of the galvanometer downward to a scale just above the table. (Siemans and Halske.) This vertical mounting with scale that can be read by daylight saves a great deal of room. The galvanometer is braced securely and does not vibrate. To protect it from the dust it is covered with a thin copper hood. The resistance of the moving system is 45 ohms and there is a ballast resistance of 200 ohms in series, which, however, is not used.

Most of the precision switches used were furnished by Siemans and Halske, Catalogue Number 17327. One of similar design was made in our own shop. A new device which has given great satisfaction has been introduced into the switch connecting thermopiles with galvanometer. At the start of the experiment, or at any other time when the temperature differences between outer and inner walls are large, a resistance of $300 \mathrm{ohms}$ is kept in series. As soon as the calorimeter is in balance a button on the switch is turned and the resistance shortcircuited, making the adiabatic control extremely delicate. The Kohlrausch bridge provided by the Leeds and Northrup Company of Philadelphia is similar to the one described by Williams. The 60-step rheostat for controlling the temperature of the ingoing water and the four 45-step theostats controlling that of the ingoing air, bottom, sides and top of the outer copper wall, were made by the Simplex Heater Company of Cambridge, Mass. They are mounted on the back of the board with their handles projecting through the board to the observer's 
table. Just above them on the back of the marble slab are the five tube rheostats (Siemans and Halske) used to cut down the current to various small pieces of apparatus. On the front of the board are the two relays, one for the Williams water heating resistance and current regulator and the other for the Gouy regulator.

The thermopiles between outer and inner copper walls are arranged in three groups, thirty-two on the top, thirty on the sides and twelve on the bottom, the area covered by each group being warmed by a strand of enamelled "Therlo Wire," No. 24 B \& S gauge, whose temperature is controlled by one of the step rheostats.

One thermopile is arranged with one end in the outgoing air current and the other in the ingoing air. The temperature of the latter is adjusted to that of the former by means of a step rheostat and two 55 volt lamps. A similar rheostat controls the temperature of the ingoing water by means of the water heating resistance.

\section{THERMOMETERS}

All thermometers contain 100 ohms resistance in nickel or platinum wire and are made on the three-lead system, being read on the same galvanometer used for the thermopiles. The water thermometers made by Leeds and Northrup are similar to those constructed by them for the automatic calorimeter of the Department of Agriculture. They are described in the Leeds and Northrup catalogue (Bulletin 811) and also by Dickinson and Mueller $^{\top}$ of the United States Bureau of Standards. In our hands they have been most satisfactory, since they are more accurate, easier to calibrate, and easier to read than mercurials. The Leeds and Northrup air thermometer, similar to that used by Williams, is in eight divisions scattered over the inside of the box so as to give the average temperature of the air. They are connected in series by copper wire covered with rubber and a casing of lead, a combination made especially for us which has given good service. The wall thermometer consisting of eight divisions in series was made in this laboratory. Each division was made of No. 38 double silk covered nickel wire wound around a strip of mica and held 2 or $3 \mathrm{~mm}$. from the inside of the inner copper wall. Over this was soldered a shallow copper box so that the resistance wire would lie in a small air space completely surrounded by metal at the temperature of the wall.

The rectal thermometer is of a new design made to respond more rapidly to changes in the temperature than the old type in which the resistance wire was surrounded by a jacket of dead air. The nickel wire with its double silk covering is wound on a small piece of ivory

7. Dickinson and Mueller: New Calorimetric Resistance Thermometers, Bull. Bureau Standards, 1913, ix, 483. 
and dipped in a round ended silver tube filled with molten Wood's fusible alloy at a temperature of $96 \mathrm{C}$. This is solidified by dipping in water, thus forming direct metallic contact between the outside of the silver tube and the insulated wire. The leads from the thermometer are enclosed in a soft rubber tube. The surface thermometers are made of flat circular buttons of ivory $25 \mathrm{~mm}$. in diameter and $5 \mathrm{~mm}$. thick. One side of the button is hollowed out to a depth of $3 \mathrm{~mm}$., the edges being filleted. On the bottom of this depression is wound concentrically the resistance wire. On this is poured the molten Wood's metal until it is flush with the original level of the ivory. Two of these units are used in series in each of the two surface thermometers. They are strapped to the skin with adhesive plaster and covered with a pad of cotton wool about $20 \mathrm{~cm}$. in diameter and $4 \mathrm{~cm}$. thick, this also being held in place with adhesive plaster.

The air thermometers were calibrated by the makers and the wall thermometers made to contain exactly the same resistance. Since they are used only to denote relative changes in temperature, a more exact calibration is not necessary. The rectal, surface and water thermometers are standardized several times a year by means of very accurate mercurials, certified by the Physikalische Technische Reichsanstalt. When calibrating them one notices that the electric thermometers all respond to temperature changes much more quickly than the mercurials.

The flexible rubber covered leads from the surface and rectal thermometers and the lead covered wires from the wall and air thermometers are carried to a ten-wire cable which perforates the calorimeter walls and is distributed on a hard rubber plate attached to the calorimeter and thence carried to the switches on the observer's table. The high tension currents from the calorimeter pass to a small hard rubber plate inside the box, thence in a separate strand cable to a slate board outside the calorimeter, and thence to the rheostat board. This cable carries leads for the telephone, electric fan and for the resistance coil used in electric checks.

\section{ACCESSORY API'ARATUS}

The telephone, which has been madc as light as possible, is seldom used, since the muscular work involved in telephoning is enough to affect seriously the results in rest experiments. The small electric fan placed in a corner at the foot of the calorimeter stirs the air thoroughly and allows one to get a good sample by drawing off ten liters through the large Bohr meter attached to the outgoing air pipe. The fan is run by the Edison storage batteries, giving off approximately 4.5 calories an hour, the exact amount being determined once an hour by a voltmeter and ammeter. 
On the right side of the subject is a small glass shelf for the weighed urine bottles which, after each voiding, are placed on a spring balance that can be read through the window. Two small brass tubes are led through the wall of the calorimeter just below the small window. One acts as an emergency vent to prevent a positive or negative pressure at the beginning or end of an experiment when the ventilation is stopped. To the other is attached the Bowles stethoscope, which is strapped over the apex of the heart so that an observer outside can count the pulse at frequent intervals.

The insicle of the calorimeter is formed by the polished tinned copper, the roof being almost hidden by the longitudinal absorber pipes wound with brass "jack chain." The calorimeter is wide enough for a man to turn comfortably from side to side, high enough at the foot to allow him to cross his legs and high enough at the head to allow him to sit upright.

THE BED

The bed in its present form is the result of much experimentation. The frame is made of varnished oak raised at the head so that the top is $12.7 \mathrm{~cm}$. from the floor of the calorimeter while it is raised only $8.2 \mathrm{~cm}$. at the foot. This allows for the sag of the waterproof canvas laced in the frame and keeps the subject 2 to $3 \mathrm{~cm}$. from the copper floor. At the head is a back-rest with a piece of water-proof canvas, which is usually supplemented by a soft pillow. The bed is mounted on a pair of skids so that it can be pushed from the stretcher into the box. The canvas has proved to be much more comfortable than the springs and blankets formerly employed and has the advantage of absorbing very little water vapor. The varnished wood absorbs some water, the necessary clothing of the patient a great deal more, while the polished walls absorb only a minimum.

\section{ELECTRIC AND ALCOHOL CONTROL EXPERIMENTS}

The calorimeter has been tested repeatedly by dissipating known amounts of heat in resistance coils and by burning known amounts of alcohol. The apparatus and procedure used correspond almost exactly with those described by Williams and are similar to those previously used by Atwater and Benedict and by Benedict, Riche and Emmes. ${ }^{8}$ In calculating the latent heat of the evaporation of water we have adopted the figures of Smith ${ }^{\circ}$ and have given the latent heat the value of 0.584 large calories per gram of water evaporated at $23 \mathrm{C}$., the usual experimental temperature.

8. Benedict, Riche and Emmes: Control Tests of a Respiration Calorimeter, Am. Jour. Physiol., 1910, xxvi, 1.

9. Smith, A. W.: Heat of Evaporation of Water, Physical Review, 1907, $\mathrm{xxv}, 145$. 


\begin{tabular}{|c|c|c|c|}
\hline \multicolumn{2}{|c|}{ 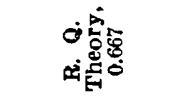 } & 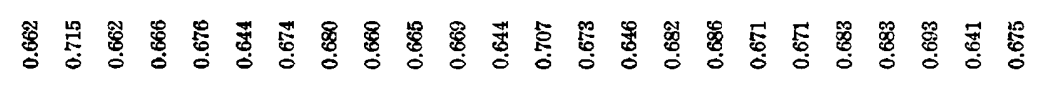 & 管 \\
\hline \multirow{3}{*}{ 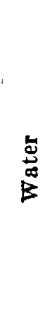 } & 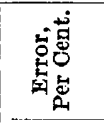 & 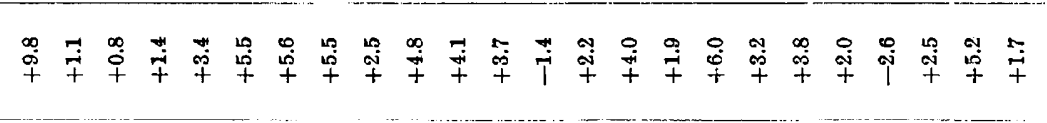 & 密 \\
\hline & 言呈 & 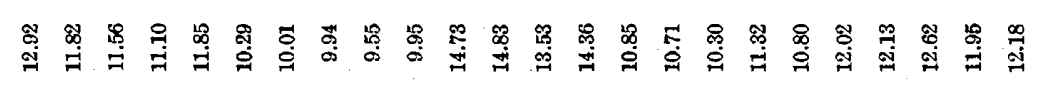 & 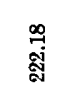 \\
\hline & 悹高 & 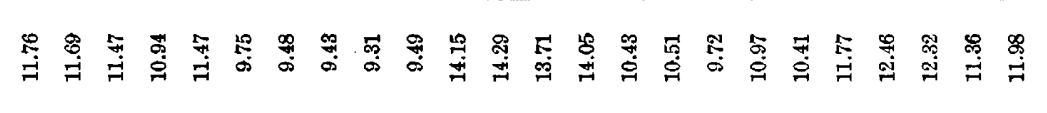 & 㩊 \\
\hline \multirow{3}{*}{ 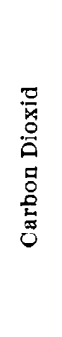 } & 䇏高 & 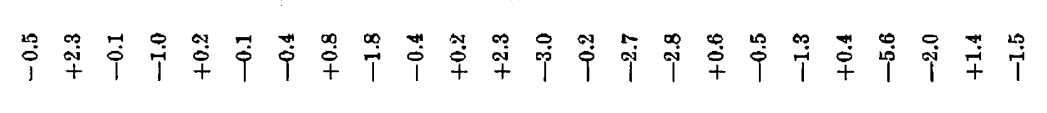 & $\stackrel{m}{i}$ \\
\hline & 善息 & 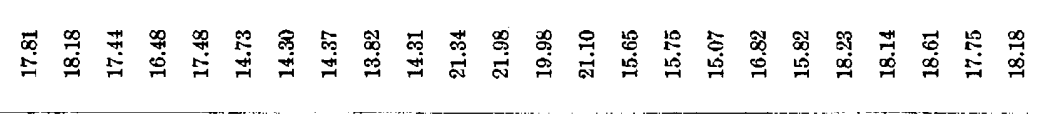 & 品 \\
\hline & 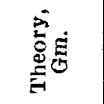 & 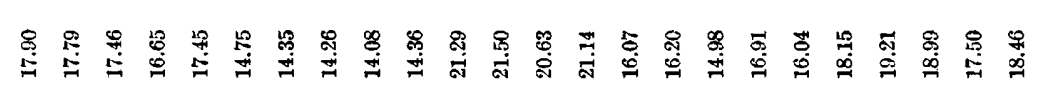 & 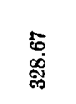 \\
\hline \multirow{3}{*}{ 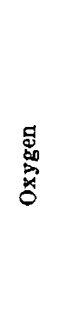 } & 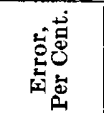 & 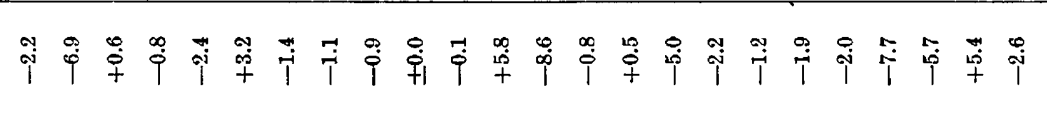 & $\stackrel{8}{i}$ \\
\hline & 害章 & 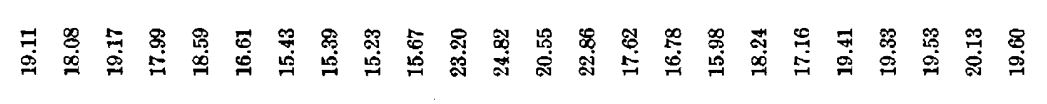 & 8 \\
\hline & 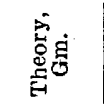 & 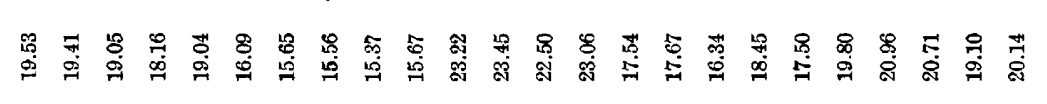 & 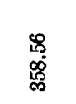 \\
\hline \multirow{5}{*}{ 莺 } & 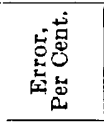 & 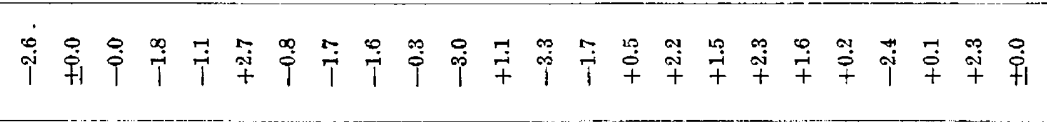 & $\stackrel{\alpha}{q}$ \\
\hline & 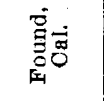 & 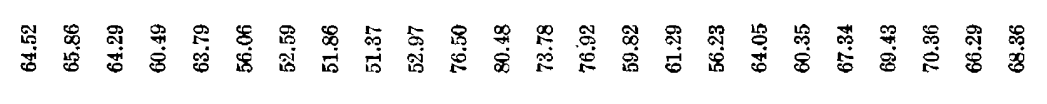 & 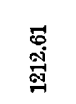 \\
\hline & 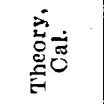 & 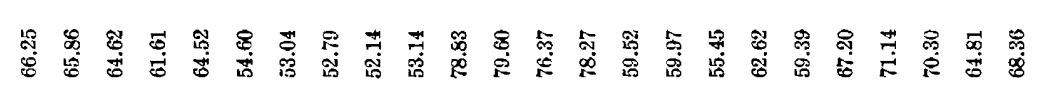 & 产 \\
\hline & 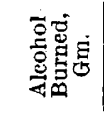 & 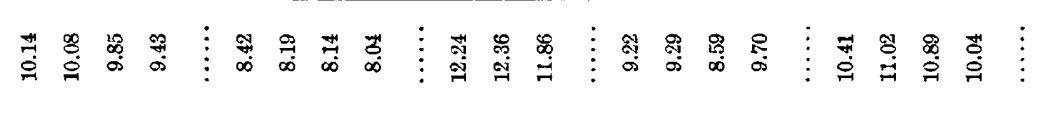 & $\vdots$ \\
\hline & 言 & - & $:$ \\
\hline \multicolumn{2}{|c|}{ 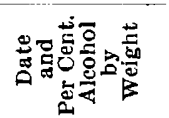 } & 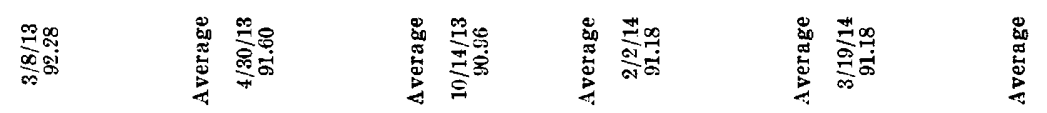 & 妾 \\
\hline
\end{tabular}


It has seemed advisable to publish all the electric and alcohol checks made with the calorimeter. In publishing control tests the results are much more striking if one selects only the best and leaves out those in which the agreement is not close. This method expresses only the minimum error while the things we really need to know are the average, maximum and total errors. The total error shows the accuracy of the method, the maximum error may occur in the course of any experiment, while the average error is with us always. The minimum error

TABLE 2.-Electric Checks

\begin{tabular}{|c|c|c|c|c|c|c|c|c|c|}
\hline Date & $\begin{array}{l}\text { Length } \\
\text { of } \\
\text { Period, } \\
\text { Min. }\end{array}$ & $\begin{array}{l}\text { Calories, } \\
\text { Theory }\end{array}$ & $\begin{array}{l}\text { Calories, } \\
\text { Found }\end{array}$ & $\begin{array}{l}\text { Per Cent } \\
\text { Error }\end{array}$ & Date & $\begin{array}{l}\text { Length } \\
\text { of } \\
\text { Period, } \\
\text { Min. }\end{array}$ & $\begin{array}{c}\text { Calories, } \\
\text { Theory }\end{array}$ & $\begin{array}{l}\text { Calories, } \\
\text { Found }\end{array}$ & $\begin{array}{l}\text { Per Cent. } \\
\text { Error }\end{array}$ \\
\hline \multirow[t]{2}{*}{$3 / 4 / 13$} & 60 & 72.25 & 73.19 & +1.2 & \multirow[t]{2}{*}{$11 / 28 / 13$} & 60 & 78.22 & 77.15 & -1.4 \\
\hline & 60 & 72.25 & 72.19 & +0.0 & & 60 & 78.22 & 77.62 & -0.8 \\
\hline Average & . & 72.25 & 72.69 & +0.6 & \multirow[b]{2}{*}{ Average } & 60 & 78.22 & 78.67 & +0.6 \\
\hline $4 / 5 / 13$ & 60 & 80.78 & 77.26 & -4.4 & & .. & 78.22 & 77.81 & -0.5 \\
\hline \multirow[b]{2}{*}{ Average } & 60 & 80.78 & 79.31 & -1.8 & \multirow{2}{*}{$1 / 26 / 14$} & 60 & 76.92 & 75.86 & \multirow{2}{*}{-1.4} \\
\hline & $\cdots$ & 80.78 & 78.29 & -3.1 & & 60 & 76.92 & 77.41 & \\
\hline \multirow[t]{5}{*}{$10 / 13 / 13$} & 30 & 41.74 & 42.15 & +1.0 & \multirow{4}{*}{ Average } & 60 & 76.92 & 77.88 & $\begin{array}{r}+0.6 \\
+1.3\end{array}$ \\
\hline & 30 & 41.74 & 41.56 & -0.4 & & \multirow{2}{*}{60} & \multirow{2}{*}{76.92} & \multirow{2}{*}{77.24} & \multirow{3}{*}{$\begin{array}{l}+0.4 \\
+0.2\end{array}$} \\
\hline & 30 & 41.74 & 41.25 & -1.2 & & & & & \\
\hline & 30 & 41.74 & 41.10 & -1.5 & & $\cdots$ & 10.02 & 17.10 & \\
\hline & 30 & 41.74 & 41.35 & -0.8 & $5 / 11 / 14$ & $60 \mathrm{~A}$ & 78.71 & 80.03 & * \\
\hline Average & .. & 41.74 & 41.49 & -0.6 & & $60 \mathrm{~B}$ & 78.22 & 75.18 & $\ldots$ \\
\hline \multirow[t]{4}{*}{$10 / 22 / 13$} & 60 & 83.98 & 83.98 & \pm 0.0 & \multirow{3}{*}{ Total.... } & \multirow{3}{*}{$\begin{array}{c}30 \mathrm{C} \\
150\end{array}$} & \multirow{3}{*}{$\begin{array}{r}39.07 \\
196.00\end{array}$} & 41.35 & \multirow{3}{*}{$\begin{array}{c}\cdots \\
+0.3\end{array}$} \\
\hline & 60 & 83.98 & 83.83 & -0.2 & & & & 196.56 & \\
\hline & 60 & 83.98 & 84.02 & +0.0 & & & & & \\
\hline & 60 & 83.98 & 83.84 & -0.2 & & & & & \\
\hline Average & .. & 83.98 & 83.92 & -0.1 & all checks & .. & 1589.02 & 1583.42 & -3.5 \\
\hline
\end{tabular}

* A, B, C. Temperature changes of wall of calorimeter: A, $+0.06 \mathrm{C}$; B, $-0.73 \mathrm{C} . ; \mathrm{C},-0.05 \mathrm{C}$. Test to verify hydrothermal equivalent.

is a joy to behold, but it does not occur with the regularity inferred by the prominence it is ustually given. If, for instance, we should publish only the electric check of October 22 with an hourly error of 0.2 per cent., and the alcohol check of April 30, in which the total errors in the measurement of heat, oxygen and carbon dioxid are all less than $1 / 2$ of 1 per cent., we should give a false impression of accuracy. This test shows that the calorimeter is capable of neastiring heat, oxygen and carbon dioxid with a maximum error of 1.8 per cent. in three consecutive hours. Even better results could be obtained if greater care were taken to secure an even combustion of alcohol. On the other 
hand, the errors which can occur in hourly periods and in whole experiments are shown in Table 3 . The average error has been obtained by multiplying each per cent. of error by the number of times it occurs and dividing the total by the number of periods. In the whole series of experiments of three or four hours' duration the average error for heat is 0.9 per cent., for oxygen 1.6 per cent. and for carbon dioxid 0.6 per cent., while for the individual hours the error is 1.2 per cent., 3.2 per cent. and 1.6 per cent., respectively. The total error in all the

TABLE 3.-Summary of Errors in Electric and Alcohol Checks

\begin{tabular}{|c|c|c|c|c|c|c|c|c|}
\hline \multirow{2}{*}{$\begin{array}{l}\text { Per cent. } \\
\text { Error }\end{array}$} & \multicolumn{4}{|c|}{ Average of Whole Expcriment } & \multicolumn{4}{|c|}{ Individual Hours } \\
\hline & Cal. & $\mathrm{O}_{2}$ & $\mathrm{CO}_{7}$ & $\mathrm{H} \rightleftharpoons \mathrm{O}$ & Cal. & $\mathrm{O}_{2}$ & $\mathrm{CO}_{2}$ & $\mathrm{H}=\mathrm{O}$ \\
\hline $0 \ldots \ldots \ldots \ldots \ldots$ & 5 & 1 & 3 & $\cdots$ & 10 & ] & 5 & .. \\
\hline $1 \ldots \ldots \ldots \ldots \ldots$ & 4 & 1 & 1 & $\cdots$ & 15 & 7 & 5 & 4 \\
\hline $2 \ldots \ldots \ldots \ldots \ldots$ & 2 & 2 & $:$ & 2 & 9 & 3 & 5 & 2 \\
\hline $3 \ldots \ldots \ldots \ldots \ldots$ & 1 & 1 & .. & 1 & 4 & 1 & 3 & 4 \\
\hline $4 \ldots \ldots \ldots \ldots \ldots$, & $\because$ &. & . & 1 & 1 & .. & .. & 3 \\
\hline $5 \ldots \ldots \ldots \ldots \ldots$ & .. & $\cdots$ & $\cdots$ & 1 & $\cdots$ & 2 & .. & 1 \\
\hline $6 \ldots \ldots \ldots \ldots \ldots$ & .. & $\ldots$ & .. & . & $\cdots$ & 2 & 1 & 4 \\
\hline $7 \ldots \ldots \ldots \ldots \ldots$ & .. & .. & $\cdots$ & $\cdots$ & . & 1 & 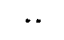 & .. \\
\hline $8 \ldots \ldots \ldots \ldots \ldots$ & .. & $\cdots$ & -. & $\because$ & .. & 1 & . & .. \\
\hline $9 . \ldots \ldots \ldots \ldots \ldots$ & *. & .. & $\cdots$ & $\because$ & .. & 1 & $\cdots$ & . \\
\hline $10 \ldots \ldots \ldots \ldots \ldots$ & .. & .. & .. & $\cdot \cdot$ & .. & .. & $\because$ & 1 \\
\hline $\begin{array}{c}\text { Total number of } \\
\text { experiments or } \\
\text { hours.......... }\end{array}$ & 12 & 5 & 5 & 5 & 39 & 19 & 19 & 19 \\
\hline Average error... & 0.9 & 1.6 & 0.6 & 3.2 & 1.2 & 3.2 & 1.6 & 3.7 \\
\hline Total error...... & -0.33 & -1.69 & -0.68 & +3.09 & & & & \\
\hline
\end{tabular}

electric and alcohol checks is: heat, -0.32 per cent., $\mathrm{O}_{2}-1.69$ per cent., $\mathrm{CO}_{2}-0.68$ per cent. The total error in the water is +3.09 per cent.

The electric checks show a smaller error in the measurement of calories than the alcohol, since the dissipation of heat is much more uniform. It is difficult to secure an even flow of alcohol to the burner and the larger errors in the oxygen determination are due to irregularities in the flow during the last five minutes of the period. If a slight negative pressure develops within the box toward the end of the period, alcohol is sucked into the burner causing the flame to flare up 
and expand the air before the air thermometers record the rise in temperature. This causes an error in the oxygen calculation which, as the tables show, is usually corrected the next hour. With a trained human subject the production of heat and carbon dioxid and the absorption of oxygen are more regular than in the case of an alcohol check and the error presumably not so large. The cause for the negative total error in the measurement of heat, $\mathrm{O}_{2}$ and $\mathrm{CO}_{2}$, is not clear, but one cannot help suspecting that a slight absorption of water by the alcohol and a slight evaporation as the alcohol drops from the bottle into the buret may account for most of the error. In experiments on man there is another factor which reduces an error in the measurement of oxygen or carbon dioxid considerably. In calculating the indirect calorimetry the factor by which the oxygen or carbon dioxid is multiplied changes with the respiratory quotient and it happens that a plus error in measurement of the gas is partially offset by a minus change in the factor. This change reduces the error to an extent varying between one-fifth and three-quarters of its original size, unless the errors in both gases are in the same direction, leaving the quotient unaltered. The accuracy of the calorimeter has also been demonstrated by the close agreement of the methods of direct and indirect calorimetry. This will be taken up in detail in the paper on normal controls, but at this point it may be said that in a total measurement of 4,577 calories the two methods agreed within 0.17 per cent., and that in 26-hourly periods on the normal control most carefully studied, the agreement was within 5 per cent. in seventeen of the hours.

In spite of the fact that some of the errors published in the table are larger than those published in connection with other types of apparatus, we feel justified in believing that the Sage calorimeter is the most accurate and most reliable instrument of its size used in the study of the respiratory metabolism. The table includes all the alcohol and electric checks, good, bad and indifferent, made during the period when the machine was used for experiments. The only ones left out are those made at the beginning of the season while the apparatus was being put in order, and actual work was never begun before obtaining a check good enough to publish. To the best of our knowledge this method of publishing all the tests has never been used in connection with other types of respiration apparatus, and we have no detailed information as to their average, maximum and total errors.

It is to be regretted that we have not been able to make long electric tests to determine the hydrothermal equivalent of the calorimeter. The storage batteries are not powerful enough to furnish current for more than four hours in addition to the preliminary period of 30 to 40 minutes, and we have never felt justified in using the house current 
with its variations in voltage. Numerous short tests showed that the hydrothermal equivalent was very close to 19 liters of water, and this figure gave results within 0.3 per cent. in the check of May 11 with a large temperature change in the second hour. Incidentally, the advantage of a wooden frame is shown by the rapidity with which the box responded to this temperature variation.

\section{DETERMINATION OF WATER ELIMINATION}

In all types of respiration apparatus the measurement of the water elimination has presented great difficulties. This was studied in detail by Benedict, Riche and Emmes, who found that long experimental periods were required to obtain accurate results. The interior of the Sage calorimeter is tinned and polished and there is very little woodwork and cloth. but still a considerable amount of moisture can be retained within the box. In alcohol checks with a water production of only 10 to 14 grams an hour the air becomes dryer and dryer, and this moisture is given off during the whole test, making uniformly a plus error. In experiments on normal men the water elimination is about twice this amount and the percentage of moisture changes but little from hour to hour. In patients who have a tendency to sweat, the water given off may amount to 35 to 40 grams an hour, and there is a terdency for the percentage in the air to increase steadily and finally reach the point of saturation. We should expect a plus error in the determination as the air becomes dryer, a minus error as the percentage of moisture increases, and no error while equilibrium is being maintained. After the first hour of an experiment on man it seems fair to expect an error of less than 5 per cent., except in extreme cases of sweating. More accurate results could be obtained only by removing all wood-work, stripping the man naked and increasing the ventilating current. This would involve such artificial conditions that the results would be worthless.

\section{ADAPTABILITY OF CAIORIMETER}

By carefully controlling the rate of flow and the temperature of the water in the heat-absorber it is possible to adapt the calorimeter to wide variations in the heat production of the subjects. For example, on April 23, 1914, an experiment was made on a cretin with an average heat production of 26 calories an hour. The next day the subject was a patient with exophthalmic goiter, whose heat production averaged 107 calories. In one case the methods of direct and indirect calorimetry agreed within 0.2 per cent., and in the other within 0.7 per cent. It has also been possible to adapt the calorimeter rapidly to changes in the heat production from hour to hour by changing the temperature of the 
ingoing water and in extreme cases by changing the rate of flow at the beginning of a period.

It has been possible in a long series of experiments for two men to take all the readings and make all the calculations in hourly periods. Three men can handle the apparatus with ease during the trying experiments, and most of the alcohol checks, which are much more difficult, have been made with only three in the room. As a rule, the staff arrives shortly before nine o'clock in the morning, makes a three-hour experiment, gets everything in readiness for the next day and leaves the calorimeter room about three or four o'clock in the afternoon. It has been possible, on occasions, to make six experiments in a week. The calorimeter has been very seldom out of commission. Between October 13,1913 , and May 18, 1914, it was possible to make 113 experiments on man and eight alcohol and electric checks.

\section{SUMMARY AND CONCLUUSIONS}

The original Atwater-Rosa respiration calorimeter with the improvements added by Benedict, Williams and others has been adapted for clinical study in Bellevue Hospital. The form of the apparatus makes it perfectly comfortable for patients. The accuracy is such that in observations lasting three or four hours the heat production, carbon dioxid elimination and oxygen consumption as determined by alcohol and electric tests can be measured with an average error of 0.9 per cent., 0.6 per cent. and 1.6 per cent., respectively. In periods one hour long the average error for heat measurement was 1.2 per cent., for carbon dioxid 1.6 per cent. and for oxygen 3.2 per cent.

The calorimeter never needs more than three men for its operation, and two men have repeatedly made all the readings and all the calculations in hourly periods. 